\title{
Relevance and Compliance of Requests for Dental Panoramic Radiography Examination at Yaounde (Cameroon)
}

\author{
Armel Philippe Awana ${ }^{1,2}$, Ambroise Merci Seme Engoumou ${ }^{3,4}$, Mballa Amougou Jean ${ }^{5}$, \\ Goni Ismaila ${ }^{3}$, Odile Fernande Zeh $^{3,6}$ \\ ${ }^{1}$ Department of Biomedical Sciences, University of Ngaoundere, Ngaoundere, Cameroon \\ ${ }^{2}$ Yaounde Jamot Hospital, Yaounde, Cameroon \\ ${ }^{3}$ Faculty of Medicine and Biomedical Sciences, University of Yaounde I, Yaounde, Cameroon \\ ${ }^{4}$ In-Vitro Fertilisation Yaounde Gynaecological Endoscopic Surgery and Human Reproductive Teaching Hospital, Yaounde, Cameroon \\ ${ }^{5}$ Yaounde University Teaching Hospital Centre, Yaounde, Cameroon \\ ${ }^{6}$ Yaounde Gynaecology Obstetrics and Pediatrics Hospital, Yaounde, Cameroon \\ Email:*armelawana@yahoo.fr
}

How to cite this paper: Awana, A.P., Engoumou, A.M.S., Jean, M.A., Ismaila, G. and Zeh, O.F. (2020) Relevance and Compliance of Requests for Dental Panoramic Radiography Examination at Yaounde (Cameroon). Advances in Molecular Imaging, 10, 31-37.

https://doi.org/10.4236/ami.2020.104004

Received: June 25, 2020

Accepted: September 27, 2020

Published: September 302020

Copyright $\odot 2020$ by author(s) and Scientific Research Publishing Inc. This work is licensed under the Creative Commons Attribution International License (CC BY 4.0).

http://creativecommons.org/licenses/by/4.0/

\section{(c) (i) Open Access}

\begin{abstract}
Background: Research studies made in Cameroon on compliance and relevance in the various areas of imaging, show the failure to comply with administrative and clinical criteria. These research studies led to recommendations meant for result amelioration. However, the orthopantomogram (OPT) field remains less studied in that regard in Cameroon. Aim: Evaluate the relevance and compliance of examination requests for panoramic dental radiography. Setting and Design: It is a descriptive cross-sectional study with a consecutive sample of dental panoramic requests identified during the study period in 4 radiology centres of Yaoundé. Material and Methods: Variables studied here were the validity criteria of imaging examination. Request: Five of which are of administrative order (date of the request, requesting department, patient's identity, patient's age, applicant's identity) and three of clinical order (anatomic region, reason for the examination and the purpose of the examination). Statistical Analysis: Chi-squared test was used with confidence interval of $95 \%$. Results: Patient's identity (name) was the criteria carrying the highest information (98.9\%), followed by the name of the applicant physician (91.6\%). Out of 179 requests analysed, $8.6 \%$ had complete information. $46.4 \%$ of requests had no indications. Dental surgeon was the top prescriber with a total of 112 (62.6\%). Conclusion: The quality of dental panoramic requests was not optimal in Yaounde, with lack of precision mostly noted at the level of clinical criteria.
\end{abstract}




\section{Keywords}

Compliance, Relevance, Request, Panoramic Dental, Orthopantomogram

\section{Introduction}

Every request made for radiological examination must respond to a given number of known administrative and clinical criteria [1] [2]. In our environment, the request for orthopantomogram (OPT) examination is increasing. This less radiating examination is highly demanded for his numerous indications both diagnostic and prognostic. So, it will be wise to take into consideration all elements that could contribute to the optimisation of this examination, minimization of expenses, errors diagnosis, therapeutic wandering and useless examinations.

The optimisation of this examination will go through a request respecting the criteria relating to radiology examinations.

The French National Authority for Health (HAS) as well as other enterprises and schools advocate certain recommendations for a well-written request for imaging examination. These recommendations set the criteria to follow during the prescriptions of requests. These include eight criteria, five of which are of administrative order (date of the request, requesting agency, patient's identity, patient's age, applicant's identity) and three of clinical order (anatomic region, reason for the examination and the purpose of the examination).

The purpose or the question asked by the clinician enables the radiologist to know what he is searching for and to give him an answer acting as an orientation or a confirmation [3].

Research studies made in Cameroon on compliance and relevance in the various areas of imaging, show the failure to comply with administrative and clinical criteria. These research studies led to recommendations meant for result amelioration. However, the orthopantomogram (OPT) field remains less studied in that regard [4] [5].

This situation brings us to question ourselves about the compliance and the relevance of requests for panoramic dental radiography examinations.

\section{Methods}

\subsection{Type of Study}

We conducted a descriptive cross-sectional study aimed at evaluating the compliance and the relevance of requests for panoramic dental radiography examination. The research study was carried out in four medical imaging centres of Yaounde from January to March 2018.

\subsection{Procedure}

We proceeded to a comprehensive consecutive sampling of OPT requests collected during the study period. Data was collected on a technical form, both 
anonymous and individual, prepared in advance. All collected requests were taken into consideration and examination reports were consulted in the data base of the various centres. Variables studied were the validity criteria of requests for imaging examination. This includes eight criteria, five of which are of administrative order (date of the request, requesting department, patient's identity, patient's age, applicant's identity) and three of clinical order (anatomic region, reason for the examination and the purpose of the examination).

\subsection{Statistical Analysis}

Percentage comparison was made with the help of Chi- 2 with a trusted interval of $95 \%$.

\section{Results}

\subsection{Overall Criteria Compliance}

Generally, we observed that out of the 179 collected requests, administrative criteria contained more information than clinical criteria (Table 1).

Patient's identity (name) was the criteria carrying the highest information (98.9\%), followed by the name of the applicant physician (91.6\%). The requesting department was the criteria carrying the less information (46.9\%). Patient's age gave information on $48.7 \%$ of requests. The reason for the examination and the anatomical region were respectively present on $52.5 \%$ and $50.8 \%$ of requests.

\subsection{Overall Compliance of Request}

Table 2 shows the compliance of request. 15 requests, that is $8.4 \%$, had complete information. $69.8 \%$ of requests were made up of at least 5 of the 8 criteria.

Table 1. Summary of the various criteria compliance.

\begin{tabular}{cccc} 
Criteria & Informed (\%) & Uninformed (\%) & Total (\%) \\
Date of the request & 87.7 & 12.3 & 100 \\
Requesting department & 46.9 & 53.1 & 100 \\
Name of the applicant physician & 91.6 & 08.4 & 100 \\
Identity of the patient & 98.9 & 01.1 & 100 \\
Age patient & 48.7 & 50.3 & 100 \\
Anatomic region & 50.8 & 49.2 & 100 \\
Reason for the examination & 52.5 & 47.5 & 100 \\
Purpose for the examination & 47.5 & 52.5 & \\
\hline
\end{tabular}

Table 2. Compliance rate of requests.

\begin{tabular}{ccccccccccc}
\hline Total number of criteria present & 1 & 2 & 3 & 4 & 5 & 6 & 7 & 8 & Total \\
\hline Frequency (n) & 01 & 05 & 17 & 31 & 46 & 35 & 29 & 15 & 179 \\
Percentage (\%) & 0.6 & 2.8 & 9.5 & 17.3 & 25.7 & 19.5 & 16.2 & 8.4 & 100 \\
\hline
\end{tabular}




\subsection{Qualifications of Prescribers}

Dental surgeons were the top prescribers with a total of $112(62.6 \%)$, other physicians came in second position with a total of $36(20.1 \%)$. This included maxillofacial, ENT surgeons and general practitioners with $8.4 \%, 5.6 \%$ and $3.4 \%$ respectively. We observed a non-precision qualification rate of 25 (14.5\%) prescribers. Figure 1 presents the number of prescribers according to their qualification.

\subsection{Indications (Clinical Diagnosis)}

In our research study, $46.4 \%$ of requests had no indications. Facial trauma constituted the most represented indication accounting for $15.6 \%$ of the whole requests (Table 3).

\section{Discussion}

The aim of our research study was to analyse the requests for panoramic dental radiography examination in the town of Yaounde. The objective was to determine the compliance and relevance of these requests in relation to the French High Authority of Health (HAS). We analysed 179 collected requests in three months, in 4 centres having dental panoramic service.

\subsection{Quality of the Prescriber}

As for the examination prescription, we observed that dental surgeons were the first prescribers. This tendency could be explained by the fact that majority of panoramic indications are of the dental surgeons field. He is the specialist mostly familiar with the pathology related to the major indications of dental panoramic radiography.

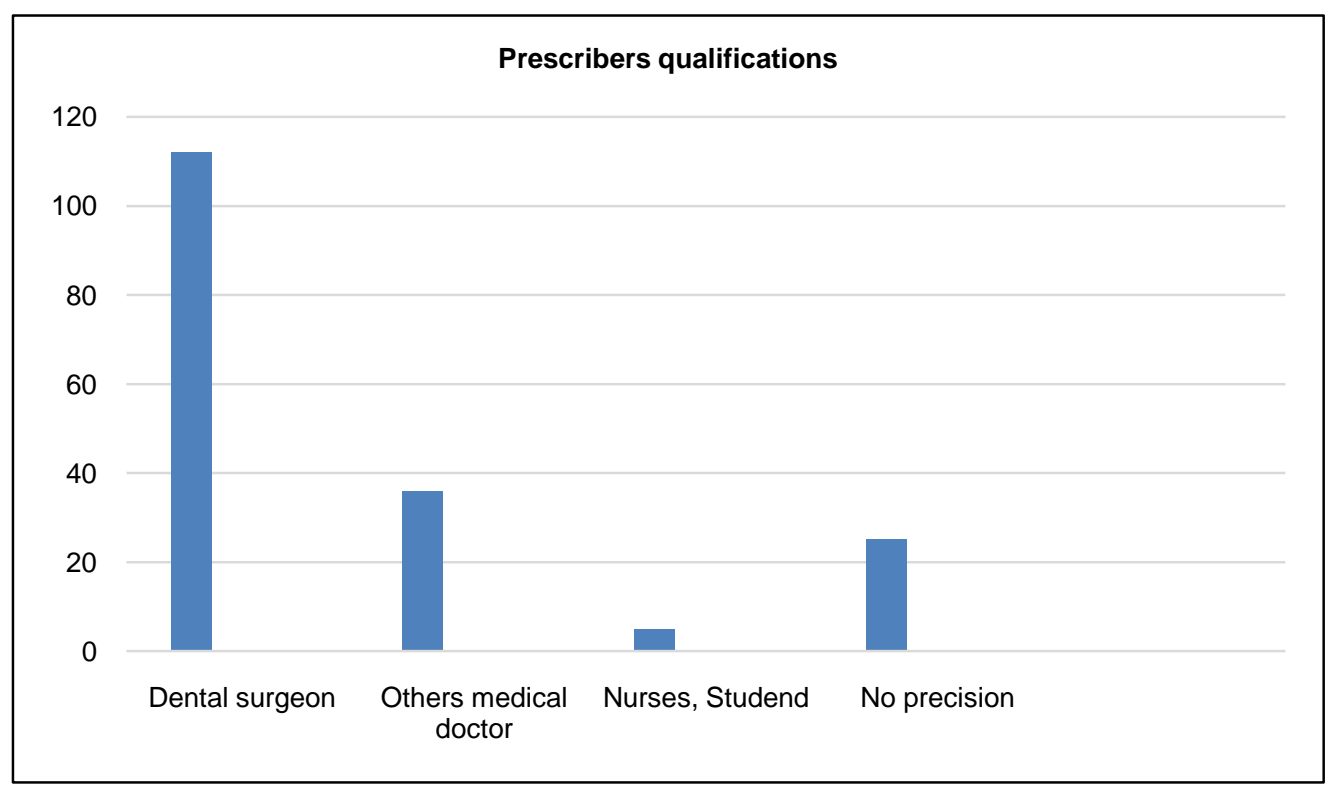

Figure 1. Frequency of prescribers according to their qualifications. 
Table 3. Clinical diagnosis found in requests.

\begin{tabular}{ccc}
\hline Indications & Frequency (n) & Percentage (\%) \\
\hline Unspecified & 83 & 46.4 \\
Facial trauma & 28 & 15.6 \\
Tumour, inflammations, infections, abscess, cysts & 15 & 8.4 \\
Pains, ATM dysfunction & 13 & 7.22 \\
Dental and pre-surgical check-ups or other treatments & 12 & 6.72 \\
Mobility, pains, dental trauma & 10 & 5.56 \\
Facial asymmetries, growth abnormalities & 06 & 3.4 \\
Deep and multiple caries & 03 & 1.7 \\
Periodontal disease & 02 & 1.1 \\
Prosthetic and implant care & 02 & 1.1 \\
Dental inclusion and malposition & 02 & 1.1 \\
Distulas and sinus infection & 01 & 0.6 \\
Dental extraction and problems of root remains & 01 & 0.6 \\
Odonto-stomatologic localization of systematic disease & 01 & 0.6 \\
\hline
\end{tabular}

\subsection{Quality (Compliance Criteria) of the Requests}

In our research study, fifteen requests were $100 \%$ compliant. This rate is superior to the one obtained by Moifo and al [4] who found $1.1 \%$ compliance on a sample of 262 collected requests within two months.

\subsubsection{Prescription Date of Requests}

On about $87.7 \%$ of OPT examinations requests were found prescription date. The prescription date is essential because from it, the validity period of the request can be approximated. These results are close to those of HAS and Moifo and al which were of $90 \%$ and $92 \%$ respectively [1] [4]. Togola, at Bamako in 2014 during a thesis on "compliance indicators for imaging examination requests in radiology and nuclear medicine department of Chu point G", found that $99 \%$ of requests were compliant so far as the date of prescription is concerned [6].

\subsubsection{Identity of the Patient}

Our results are similar to those of Togola, Moifo and Irurhe [4] [6] [7] in sub-Saharan Africa. These results may be explained by the fact that patient's identification is filled first in examination requests.

\subsubsection{Patient's Age and Sex}

The age and sex of the patient were absent on the examination requests in 50.3\% and $15.6 \%$ of cases. The absence of these information may disturb while interpreting because there exist variations and injuries depending on age and sex. As for age, our results were inferior to those of Gbazi at Cocody in 2006, who ob- 
tained $84.60 \%$ [8]. Concerning sex, our results were superior to those of Gbazy who found that on $32 \%$ of requests sex carried no information. This tendency could be explained by the fact that most of the prescribers were dental-surgeon and they found it redundant repeating these indications.

\subsubsection{Requesting Department}

The requesting department was not mentioned in $53.1 \%$ of requests. Our results were closed to those of Moifo and al [5] who obtained $63 \%$ of requests with the requesting department absent. However, they were superior to those of Gbazy [8] who found $34.45 \%$, but still much more inferior to HAS [1]. This could be explained by the fact that some requests came from private dental clinics considered as precise departments.

\subsubsection{Qualification of the Prescriber's Department}

As for the prescriber's qualification, our result is superior to that of Moifo and al [4] who obtained an attendance rate of $77.1 \%$. The origin of this difference results from the awareness in previous works.

\subsubsection{Anatomical Region of the Supposed Injury Acknowledgements}

Our result is inferior to that of HAS [1] and K. Togola who obtained $98 \%$ and 99.5\% respectively. Some prescribers consider dental panoramic as a precise examination centred on one region. Thus, dental panoramic permits the study of four different regions of which the accuracy will enable the radiologist readjust the device's parameters and to concentrate his research on a specific area during the examination.

\subsubsection{Reason for the Examination}

Our result is close to that of Moifo and al in Cameroon [4] [5] who found that $40.1 \%$ lacked clinical information. It is inferior to that of Gbazy [8], who found that $5.7 \%$ of requests did not have a reason. The reason for the examination is the first important thing. This is because it justifies the examination and the technique to be used. So, the quality of the interpretation depends on these elements.

\subsubsection{Purpose for the Examination}

The percentage aim present on requests of our research study is superior to that of Gbazy [8] who found $16.8 \%$, and it is inferior to that of Moifo who found $76.3 \%$ of requests with final application [5]. This rate trends to suggest that, imaging examinations are not meant to confirm hypothesis but to orient it towards a diagnosis.

\subsection{Analysis Based on the Prescriber's Qualification}

Compliance analysis based on the prescriber's qualification show that dental-surgeons were the first prescribers (62.2\%). However the compliance rate of the various clinic criteria was not satisfying for them. None of the clinical crite- 
ria could carry up to $50 \%$ information. This result could be drawn from the fact that most dental surgeons interpret themselves their shots and therefore would not see the need to give these information to radiologists.

\section{Conclusion}

Further to this study of which the general objective was to evaluate the compliance and relevance of requests for dental panoramic radiography in Yaoundé, we conclude that the quality of dental panoramic requests was not optimal in Yaounde.

\section{Conflicts of Interest}

The authors declare no conflicts of interest regarding the publication of this paper.

\section{References}

[1] Haute Autorité de Santé (2014) Indicateurs Pour l'Amélioration de la Qualité et de la Sécurité des Soins. Conformité des demandes d'examens d'imagerie. (consulté le 12 jan 2018).

https://www.has-sante.fr/portail/upload/docs/application/pdf/2015-07/cdei_rapport vf.pdf

[2] Haute Autorité de Santé (Projet COMPAQH). Conformité des demandes d'examens d'imagerie; cahiers des charges 2010. (consulté le 20 Nov. 2017) http://www.compaqhpst.fr/data/indicateurs/10 CDC DEI V3.pdf

[3] Neuenschwander, S. (2012) Le compte rendu radiologique et son iconographie. JFR. Paris, p 5.

[4] Moifo, B., Ndeh Kamgnie, M., Ninying Fuh, F., Zeh, O.F., Tebere, H., Moulion Tapouh, J.R., et al. (2013) Pertinence des Indications d'Examens d'Imagerie Médicale à Yaoundé-Cameroun. Health Sciences and Disease, 14, 1-8.

[5] Moifo, B., Kamgnie, M.N., Fointama, N.F., Tambe, J., Tebere, H. and Fotsin, J.G. (2014) Evaluation de la conformité des demandes d'examens d'imagerie médicale: Une expérience en Afrique subsaharienne. Médecine et Santé Tropicales, 24, 392-396. https://doi.org/10.1684/mst.2014.0382

[6] Togola, M.K. (2014) Indicateurs de conformité des demandes d'examens d'imagerie dans le service de radiologie et de médecine nucléaire du Chu point G. Thèse. Faculté de médecine et d'odontostomatologie. Université des sciences, des techniques et des technologies de Bamako, 73p.

[7] Irurhe, N.K., Sulaymon, F.A., Olowoyeye, O.A. and Adeyomoye, A.A.O. (2012) Compliance Rate of Adequate Filling of Radiology Request Forms in a Lagos University Teaching Hospital. World Journal of Medical Sciences, 7, 10-12.

[8] Gbazi, G.C. and N'gadi, K.Y. (2006) Evaluation de la demande d'examen radiologique au service d'imagerie médicale du CHU de Cocody. Journal de Radiologie, 87, 1425-1426. 